Local Magnitude Tomography in California

S. R. Ford, R. A. Uhrhammer, M. Hellweg

May 26, 2010

Bulletin of the Seismological Society of America 
This document was prepared as an account of work sponsored by an agency of the United States government. Neither the United States government nor Lawrence Livermore National Security, LLC, nor any of their employees makes any warranty, expressed or implied, or assumes any legal liability or responsibility for the accuracy, completeness, or usefulness of any information, apparatus, product, or process disclosed, or represents that its use would not infringe privately owned rights. Reference herein to any specific commercial product, process, or service by trade name, trademark, manufacturer, or otherwise does not necessarily constitute or imply its endorsement, recommendation, or favoring by the United States government or Lawrence Livermore National Security, LLC. The views and opinions of authors expressed herein do not necessarily state or reflect those of the United States government or Lawrence Livermore National Security, LLC, and shall not be used for advertising or product endorsement purposes. 


\section{$1 \quad$ Local Magnitude Tomography in California}

3 Sean R. Ford, Robert A. Uhrhammer, and Margaret Hellweg

5 Abstract

7 Lateral variation in crustal attenuation of California is calculated by inverting 25,330 synthetic

8 Wood-Anderson amplitudes from the California Integrated Seismic Network (CISN) for site,

9 source, and path effects. Two-dimensional attenuation (q or $1 / Q$ ) is derived from the path term,

10 which is calculated via an iterative least-squares inversion that also solves for perturbations to

11 the site and source terms. Source terms agree well with initial CISN $\mathrm{M}_{\mathrm{L}} \mathrm{s}$ and site terms agree

12 well with a prior regression analysis. q ranges from low attenuation at $0.001(Q=1000)$ to high

13 attenuation at $0.015(Q=66)$ with an average of $0.07(Q=143)$. The average $\mathrm{q}$ is consistent with

14 an amplitude decay function $\left(\log \mathrm{A}_{0}\right)$ for California when $\mathrm{q}$ is combined with a simple

15 geometrical spreading rate. Attenuation in California is consistent with the tectonic structure of

16 California, with low attenuation in the Sierra batholith and high attenuation at The Geysers, at

17 Long Valley, and in the Salton Trough possibly due to geothermal effects. Also, path terms are

18 an order of magnitude smaller than site and source terms, suggesting that they are not as

19 important in correcting for $\mathrm{M}_{\mathrm{L}}$.

21 Online material: Test of isotropic radiation assumption and L-curve analysis. 
25 An understanding of regional attenuation can help when interpreting of tectonic features,

26 especially their thermal structure and water content. These features have a greater influence on

27 attenuation than velocity, which is more commonly measured. The calculation of laterally

28 varying (two-dimensional, 2D) attenuation can also help to constrain earthquake parameters that

29 depend on amplitude like event magnitude. Previous studies of attenuation in California have

30 been made for one-dimensional (e.g., Erickson et al. (2004); Ford et al. (2008)) and 2D (e.g.,

31 Mayeda et al. (2005); Phillips and Stead (2008)) cases.

33 In this study we make use of recent work to recalibrate the CISN local magnitude $\left(\mathrm{M}_{\mathrm{L}}\right)$ scale

34 (Hellweg et al., 2007). The project required the calculation of Wood-Anderson amplitudes

35 measured at stations of the CISN for a good distribution of earthquakes, which resulted in over

3630,000 amplitude measurements. Inspired by the work of Pei et al. (2006), we perform an $\mathrm{M}_{\mathrm{L}}$

37 tomographic study of California and invert the amplitudes for source, site and path effects. $\mathrm{M}_{\mathrm{L}}$

38 tomography provides a unique data set and perspective for examining the crust and attenuation in

39 the frequency band that affects ordinary structures. We discuss the resultant terms and assess

40 their significance in relation to California tectonics and the measurement of $\mathrm{M}_{\mathrm{L}}$.

\section{Data and Method}

44 The $\mathrm{M}_{\mathrm{L}}$ recalibration study for the CISN (Hellweg et al. (2007)) used events with catalog

$45 \quad M_{L} \geq 3.0$ that occurred between 2000 and 2006, and in order to get an even distribution, the

46 largest event in a $50 \mathrm{~km}$ grid was selected. In an attempt to obtain more recent measurements, a 
47 second pass along this grid was made for events that occurred in 2006. This resulted in more than

48200 events. Data at distances between 1 and $500 \mathrm{~km}$ from these events measured on the

49 horizontal components was obtained from over 300 strong-motion and broadband stations of the

50 northern and southern California networks, as well as some data from temporary deployments of

51 the USArray. The Wood-Anderson seismograph response of these data were calculated

52 (Uhrhammer et al. 1996) and the maximum amplitude on the trace was measured.

54 For this study, in order to obtain a more even magnitude distribution, data for events with $\mathrm{M}>5.5$

55 were discarded. All events were recorded at more than one station. Also, if a station recorded an

56 event with more than one instrument (strong-motion and broadband) the components were

57 averaged so that each station had exactly two horizontal measurements. These criteria resulted in

58185 events recorded at 335 stations (670 components) for 25330 amplitude measurements, which

59 produced a very dense sampling of California (Figure 1a).

60

61 We employ the tomography method of Phillips and Stead (2008) where the Wood-Anderson

62 amplitude $A_{W A}$ at a given distance $r$ and frequency $f$ can be estimated by

$$
A_{W A}(f, r)=S(f) R(\theta) P(f) G(r) \exp \left(\frac{-r \pi f}{Q U}\right),
$$

65 where $S(f)$ is the source spectrum and $R(\theta)$ is the source radiation in the source-receiver direction

$66 \theta . P(f)$ is the site term, and $G(r)$ is the geometrical spreading term. The final term is an apparent

67 attenuation (parameterized by $Q$ ), where $U$ is the group velocity of the phase that produces the

68 amplitude measurement. In California, at short distances $(\sim<8 \mathrm{~km})$ this phase is the direct 
69 arrival and at greater distance $(\sim>120 \mathrm{~km})$ it is a mix of crustal and Moho/surface reflections

70 resulting in $L g$. Between these distances (80-120 km) Sn and $S m S$ are strong parts of the

71 amplitude measurement. Despite the changing contributions to the measured amplitude, we make

72 the simplifying assumption of constant $U$ equal to $3.5 \mathrm{~km} / \mathrm{s}$. This group velocity is most

73 appropriate for the phases recorded at greater distances, so some error will propagate into

74 measured $Q$, though this is assumed to be small.

75

76 The $\log$ transform of eq (1) is

77

$$
\log \left[A_{W A}(f, r)\right]=\log [S(f)]+\log [R(\theta)]+\log [P(f)]+\log [G(r)]-\frac{r \pi f}{Q U}
$$

79 We adopt a geometrical spreading term from Street et al. (1975) of the following form

80

$$
G(r)=\begin{array}{ll}
\frac{1}{r} & r<r_{0} \\
\frac{1}{r_{0}}\left(\frac{r_{0}}{r}\right)^{0.5} & r \geq r_{0}
\end{array}
$$

81

82 The distance $r_{0}$ as well as a starting 1D $Q$ model for California were found by fitting the

83 amplitude decay function $\left(\log A_{0}\right)$ used in southern California for determining local magnitude

84 (Kanamori et al., 1999),

85

$$
\log A_{0}(r)=1.11 \cdot \log (r)+(0.00189 r)+0.591,
$$


87 which is very similar to the CISN $\log \mathrm{A}_{0}$ calculated by Hellweg et al. (2007), which will be used

88 for all of California. The best fit was given by $r_{0}=200$ and $Q=150$ (Figure 2), so that the

89 spreading for the maximum amplitude transitions from body-wave $\left(r^{-1}\right)$ to surface-wave $(\sqrt{r})$ at

90 approximately $200 \mathrm{~km}$. We validate the assumption of an approximately isotropic radiation

91 pattern (Figure $\mathrm{S} 1$ in the electronic supplement to this article) so that $R(\theta)$ can be approximated

92 by a constant and the amplitudes can be corrected using eq (3) and an initial $Q$ model, then eq (2)

93 can take the form

94

$$
\log \left[A_{W A}\left(f_{W A}\right)\right]=\log \left[S\left(f_{W A}\right)\right]+\log \left[P\left(f_{W A}\right)\right]-\frac{\pi f_{W A}}{U} \int_{s} Q^{-1} d s
$$

96 where $f_{W A}$ is the frequency band of the synthetic Wood-Anderson amplitudes, which can be

97 approximated as a two-pole highpass Butterworth filter with a corner at $1.25 \mathrm{~Hz}$ (Uhrhammer

98 and Collins, 1990), and is assumed to be approximately $1 \mathrm{~Hz}$ in this analysis. The form is put

99 into a damped first-difference least-squares inversion (LSQR, Paige \& Saunders, 1982) to

100 calculate the source, site, and path terms in the Wood-Anderson band along the incremental ray

101 length, $s$. We chose a damping coefficient of 150 and a grid-spacing of $0.2^{\circ}$ based on an L-curve

102 analysis, where these 2 choices minimized the model length and residual variance satisfactorily

103 (Figure S2 in the electronic supplement to this article).

104

105 Results and Discussion

106

107 The event terms agree well with catalog magnitudes (Figure 3). The difference between the event

108 terms and catalog magnitudes (event bias) are centered on zero with a standard deviation of 0.25. 
109 Site terms agree very well with station corrections, or station-network-component-location

110 (SNCL) $\mathrm{dM}_{\mathrm{L}} \mathrm{s}$ (Figure 4). These SNCL $\mathrm{dM}_{\mathrm{L}} \mathrm{s}$ are obtained from a separate L-1 norm inversion

111 (Hellweg et al., 2007), which required historical corrections to be maintained in the current

112 algorithm. The constraint is evident in the SNCL $\mathrm{dM}_{\mathrm{L}}$ histogram, which is shifted off a mean of

113 zero. There are several outliers in this comparison. Two positive term outliers are the

114 Transportable Array (TA) stations, P05C and R05C on the north and east components,

115 respectively. This may be due to the small number of observations made during this temporary

116 installation (ten and five, respectively). The negative term outliers (gray ellipse, Figure 5) each

117 have more than sixty observations, but they are all located near the Long Valley region (Region

$118 \mathrm{~B}$, Figure $1 \mathrm{~b})$. If the SNCL $\mathrm{dM}_{\mathrm{L}} \mathrm{S}$ are correct, then the path term in this region is under-predicted,

119 which would result in a greater q (higher attenuation) in this area.

121 Resolution of the path term is calculated via direct solution of the normal equations using

122 Cholesky decomposition and the resolution length is estimated by taking the square root of the

123 ratio of grid area to diagonal resolution element (Phillips and Stead, 2008). This length is

124 contoured in Figure $1 \mathrm{~b}$ and is highest in southern California at $0.5^{\circ}$, where the network of

125 stations is dense, but a resolution of $1^{\circ}$ is found for most of California.

$127 Q$ is derived from the path term and ranges from 66 to a little more than 1000 in California. Its

128 inverse, $\mathrm{q}$, is directly related to attenuation and correlates well with geological and topographical

129 regions (Figure 1b). Attenuation is high in the geothermal regions of The Geysers, Long Valley,

130 and the Salton Trough (A, B, and D, respectively, Figure 1a) and low in the Sierra Nevada

131 batholith (C, Figure 1a). As discussed earlier, we may expect q in the Long Valley region to be 
132 even greater. There is a slight suggestion that high q may be associated with regions where

133 faulting is observed. This is most evident along the Garlock Fault (latitude $=35^{\circ}$ ) and possibly the

134 Hayward Fault system (latitude $=37.5^{\circ}$, longitude $=-121.8^{\circ}$ ). One of the most unexpected features

135 of the tomogram is the relatively low q region in the San Francisco Bay Area, and several

136 validation tests prove it to be a robust feature. Though absolute $Q$ in this region $(Q \sim 200)$ agrees

137 with Mayeda et al. (2005) and the 1-D model for the Bay Area of Malagnini et al. (2007), it

138 differs from previous work by Ford et al., (2008) $(Q \sim 100)$. The reason for the discrepancy may

139 be associated with the tectonics of the region. Ford et al. (2008) were careful only to measure

140 attenuation in the Franciscan block (west of the San Andreas Fault), however this study uses

141 paths that traverse both the Franciscan and Salinian blocks (east of the San Andreas Fault). In

142 fact, Phillips et al. (1988) found a distinct difference in coda $Q$ for the two regions, and though

143 the absolute values are different between this study and their results, the ratios of the regions are

144 similar. Furthermore, there is a suggestion in the results of Phillips and Stead (2008) that

145 attenuation in this region may be lower relative to its surroundings.

147 The path term could act as a third correction for $\mathrm{M}_{\mathrm{L}}$ in addition to the $\log \mathrm{A}_{0}$ and $\mathrm{SNCL} d \mathrm{M}_{\mathrm{L}}$

148 corrections that are already applied when calculating $\mathrm{M}_{\mathrm{L}}$ in California. However, the path

149 correction is an order of magnitude smaller than the $\log \mathrm{A}_{0}$ and $\mathrm{SNCL} \mathrm{dM}_{\mathrm{L}} \mathrm{S}(0.01$ versus 0.1 ,

150 respectively). Though, the effect of extreme $Q$ structure in regions like the Sierra Nevada, The

151 Geysers, and the Salton Trough may be large enough to warrant a path correction for paths

152 affected by those regions. 
154 Random error will not greatly affect the results presented here due to the excellent ray coverage

155 and the damping used in the inversion. However, the assumptions employed here, namely

156 isotropic radiation, and straight-line wave propagation that samples the crust will introduce

157 systematic error into the interpretation. The isotropic radiation assumption may affect the data at

158 short $(<100 \mathrm{~km})$ distances where the normalizing effects of scattering and dispersion do not play

159 a large role, whereas the wave propagation assumption may affect the data at long $(>300 \mathrm{~km})$

160 distances where the measured amplitude may belong to a diving wave that has sampled the upper

161 mantle. Finally, it is difficult to comment on intrinsic attenuation of crustal material in California

162 because this method measures a path $\mathrm{q}$ that is a combination of both intrinsic and scattering

163 attenuation.

164

165 Conclusion

166

167 We use of over 25,000 amplitude measurements made to recalibrate $\mathrm{M}_{\mathrm{L}}$ in California to derive $Q$

168 from the path term of an amplitude tomography method, which also solves for perturbations to

169 the site and source terms. Source terms agree well with initial CISN $\mathrm{M}_{\mathrm{L}} \mathrm{S}$ and site terms agree

170 well with a prior regression analysis (Hellweg et al., 2007). $Q$ ranges from 66 to 1000 with an

171 average of 143 . The average $Q$ is consistent with an amplitude decay function $\left(\log \mathrm{A}_{0}\right)$ for

172 California when combined with a simple geometrical spreading rate. Attenuation in California is

173 consistent with the tectonic structure of California, with high $Q$ in the Sierra batholith and low $Q$

174 at The Geysers, Long Valley, and Salton Trough possibly due to geothermal effects. There is

175 also increased attenuation along shear zones with active faulting. Our results in the San

176 Francisco Bay Area agree with the 1-D analysis of Malagnini et al. (2007) and 2-D study of 
177 Mayeda et al. (2005). A more complete $Q$ model may aid in ground motion estimates for

178 California. Finally, path terms are an order of magnitude smaller than site and source terms,

179 suggesting that they are not as important in correcting for $\mathrm{M}_{\mathrm{L}}$.

180

181 Data and Resources

182

183 Amplitude data for California were obtained from the Northern California Earthquake Data

184 Center (NCEDC) and the Southern California Earthquake Data Center (SCEDC) as part of the

185 forthcoming California Integrated Seismic Network (CISN) earthquake magnitude reconciliation

186 project. Some plots were made using the Generic Mapping Tools version 4.2.2

187 (www.soest.hawaii.edu/gmt; Wessel and Smith, 1998).

188

189

190 Acknowledgements

191

192 This work was performed under the auspices of the Lawrence Scholar Program and the U.S.

193 Department of Energy by Lawrence Livermore National Laboratory under Contract DE-AC52-

194 07NA27344. This is BSL contribution 10-XX.

195

196 Figures

197

198 Figure 1. a) Inset, data coverage map of California, where grid nodes $\left(0.2^{\circ}\right)$ are shaded according

199 to number of paths crossing them. Events (circles, N=185) and stations (crosses, N=335) used in 
200 the analysis are also shown. b) Local magnitude tomography of California. The scale is given in

201 Q, and q (1/Q), where hot colors (red) are high attenuation and cool colors (blue) are low

202 attenuation. Regions discussed in text are annotated: A) Geysers, B) Long Valley, C) Sierra

203 Nevadas, D) Salton Trough.

204

205 Figure 2. Amplitude decay and attenuation functions. Dark solid line is the $\log A_{0}$ used in 206 southern California (Kanamori, 1999), which is very similar to one derived for all of California 207 (Hellweg et al, 2007). Dashed line is the geometrical spreading function given in eq (3). Light 208 solid line is a constant $Q$ of 150 and dashed light line is the combination of the geometrical term 209 and the constant $Q$ plus $\mathrm{K}=0.73$.

211 Figure 3. Event term compared to catalog magnitude (CISN ML). Histograms along the axes

212 show the distributions of the event terms (top) and catalog magnitudes (right). The event terms

213 from the inversion agree well with the catalog magnitudes.

215 Figure 4. Station term compared to regression result for station-network-component-location 216 (SNCL) dML. Histograms along the axes show the distributions of the station terms (top) and the 217 SNCL dMLs (right). The station terms agree well with the regression result, but the mean is 218 shifted toward zero (as prescribed by the inversion). Two outliers (gray crosses) with a small 219 number of observations are annotated and another cluster of outliers is shown by the gray ellipse.

221 Figure S1. Corrected amplitude (crosses) variation with a) azimuth and b) distance for the 5 Feb 22205 Alum Rock $\left(\mathrm{M}_{\mathrm{W}} 4.1\right)$ earthquake. The radial (dashed line) and tangential (solid line) radiation 
223 pattern of the event is plotted in a) and the Kanamori et al. (1999) $\log A_{0}$ is plotted in b) (for

224 which the amplitudes have been corrected). The gray region in b) is the mean magnitude (4.43) \pm

$2252 \sigma(\sigma=0.36)$, where the white line is the calculated $\mathrm{M}_{\mathrm{W}}$. The catalog $\mathrm{M}_{\mathrm{L}}$ for this event is 4.42 .

226

227 Figure S2. L-curve analysis, where the damping coefficient used in the inversion that produced

228 the model and residuals is given for grid spacing of $0.2^{\circ}$. The gray line is for a grid spacing of 0.1

$229 \stackrel{\circ}{\circ}$. A damping coefficient of 150 was selected (bold type) because it minimizes the root-mean-

230 square (RMS) of the model and residual.

231

232 Berkeley Seismological Laboratory

233 (S.R.F., R.A.U., M.H.)

234

235 References

236 Ford, S. R., D. S. Dreger, K. Mayeda, W. R. Walter, L. Malagnini, and W. S. Phillips (2008).

237 Regional attenuation in Northern California: A comparison of five 1D Q methods, Bull. Seis.

238 Soc. Amer. 98 (4) 2033-2046, doi: 10.1785/0120070218.

239 Erickson, D., D. E. McNamara, and H. M. Benz (2004). Frequency-dependent Lg Q within the 240 continental United States, Bull. Seis. Soc. Amer., 94, 1630-1643.

241 Hellweg, M., R. A. Uhrhammer, K. Hutton, A. Walter, P. Lombard and E. Hauksson (2007).

242 Recalibrating ML for CISN, Eos Trans. AGU, 88 (52), Fall Meet. Suppl., Abstract S41B2430565. 
244 Kanamori, H., P. Maechling, and E. Hauksson (1999). Continous monitoring of ground-motion 245 parameters, Bull. Seis. Soc. Amer. 89 (1) 311-316.

246 Malagnini, L., K. Mayeda, R. Uhrhammer, A. Akinci, and R. B. Herrmann (2007). A regional 247 ground-motion excitation/attenuation model for the San Francisco region, Bull. Seis. Soc. $248 \quad$ Amer. 97 (3) 843-862, doi: 10.1785/0120060101.

249 Mayeda, K., L. Malagnini, W. S. Phillips, W. R. Walter, and D. S. Dreger (2005). 2-D or not 2250 D, that is the question: A northern California test, Geophys. Res. Lett. 32 (L12301), 251 doi:10.1029/2005GL022882.

252 Paige, C. C., and M. A. Saunders (1982). Algorithm 583, LSQR: Sparse linear equations and 253 least-squares problems, Trans. Math Software, 8, 195-209.

254 Pei, S. J. Zhao, C. A. Rowe, S. Wang, T. M. Hearn, Z. Xu, H. Liu, and Y. Sun (2006). ML 255 amplitude tomography in North China, Bull. Seis. Soc. Amer. 96 (4A) 1560-1566, doi: $256 \quad 10.1785 / 0120060021$.

257 Phillips, W. S., W. H. K. Lee, and J. T. Newberry (1988) Spatial variation of crustal coda Q in 258 California, Pure Appl. Geophys. 128 (1-2), 251-261.

259 Phillips, W. S. and R. J. Stead (2008). Attenuation of Lg in the western US using the USArray, 260 Geophys. Res. Lett. 35 (L07307), doi:10.1029/2007GL032926.

261 Street, R. L., R. B. Herrmann, and O. W. Nuttli (1975). Spectral characteristics of the $\mathrm{L}_{\mathrm{g}}$ wave 262 generated by central United States earthquakes, Geophys. J. R. Astro. 41, 51-63. 
263 Uhrhammer, R. A., and E. R. Collins (1990). Synthesis of Wood-Anderson seismograms from 264 broadband digital records, Bull. Seis. Soc. Amer. 80, 702 - 716.

265 Uhrhammer, R. A., S. J. Loper, and B. Romanowicz (1996). Determination of local magnitude 266 using BDSN broadband records, Bull. Seis. Soc. Amer. 86 (5), 1314-30. 


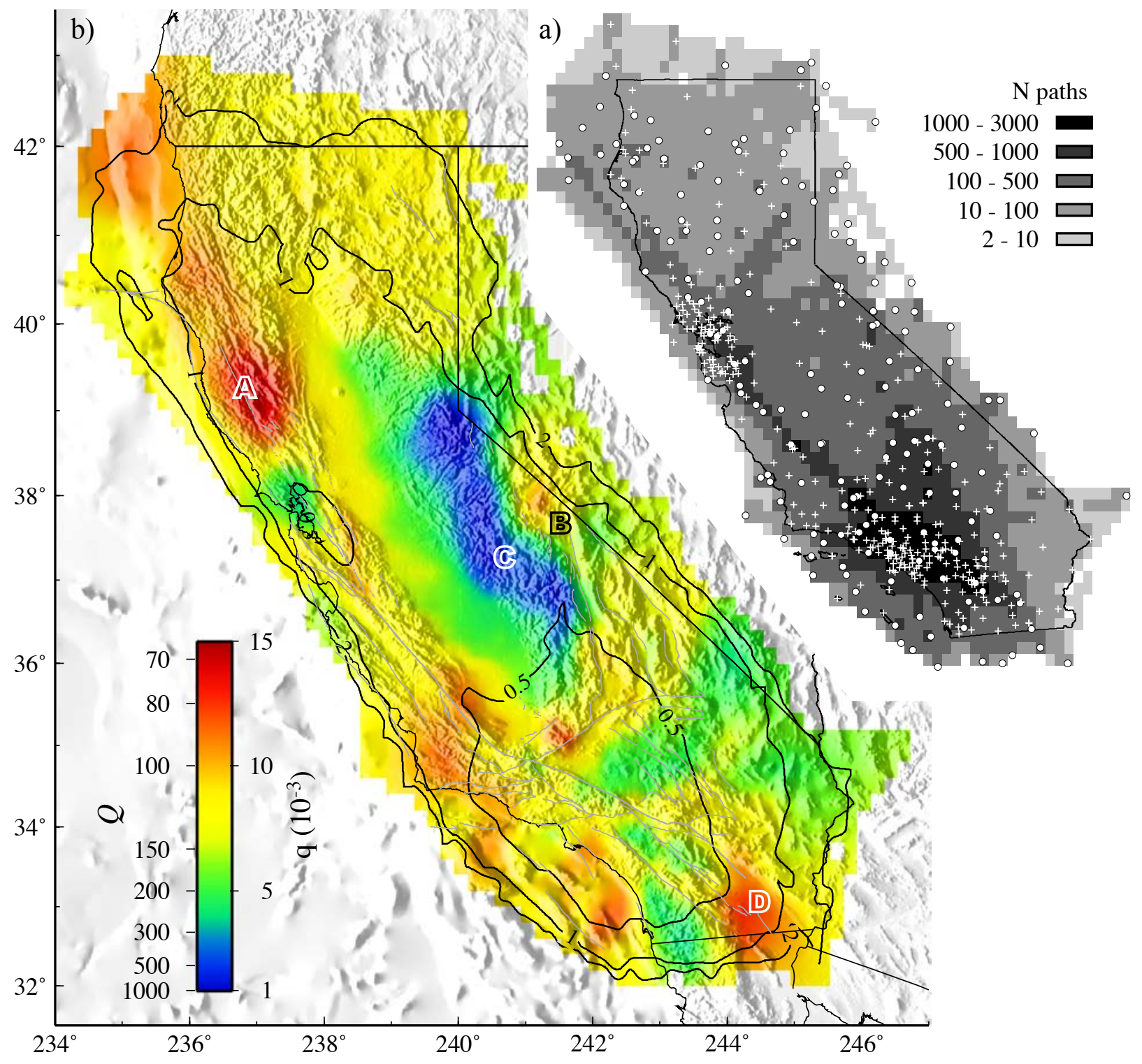

Figure 1.

Ford et al. (2009)

Version 1 


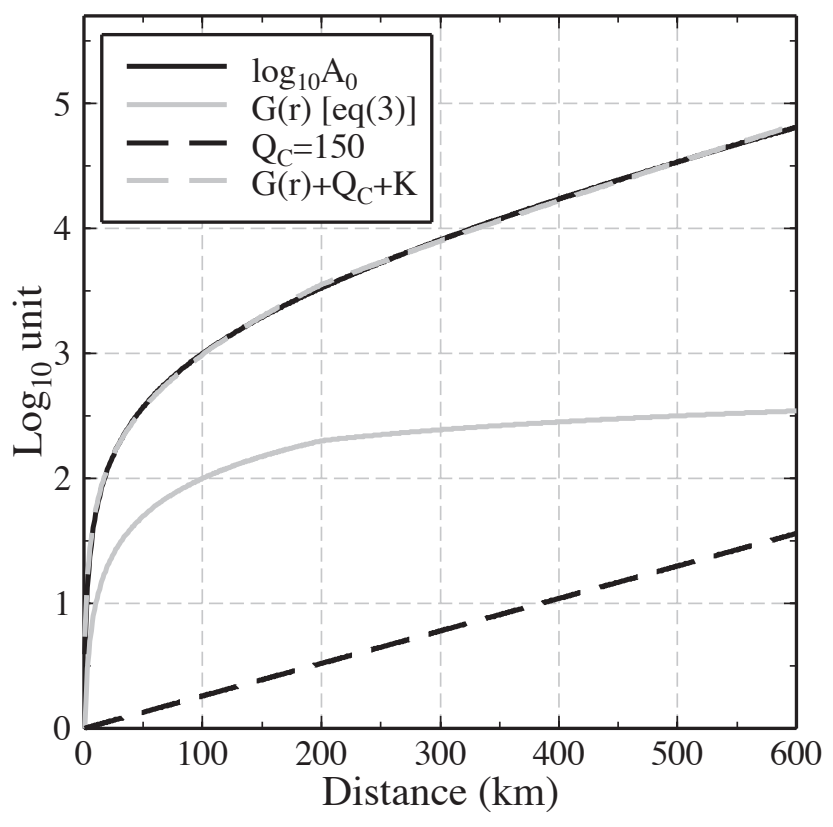

Figure 2.

Ford et al. (2009) Version 1 


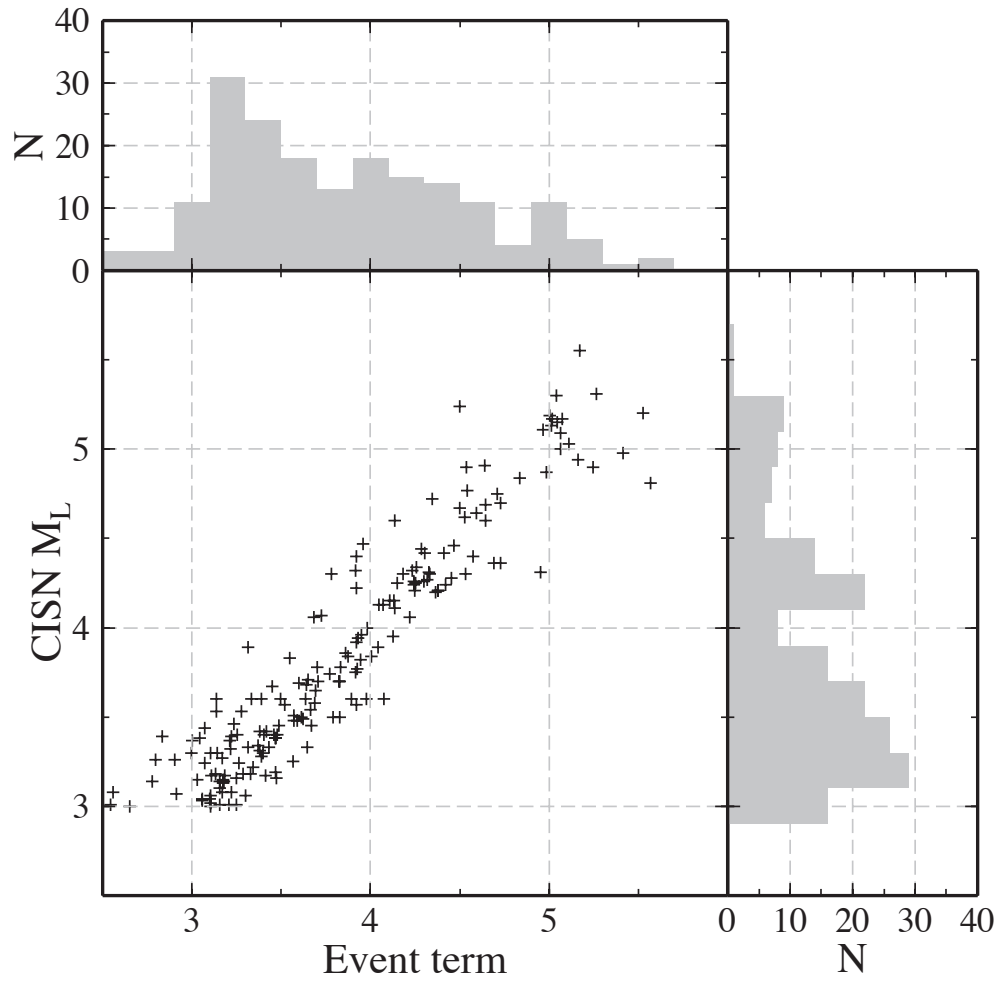

Figure 3.

Ford et al. (2009) Version 1 


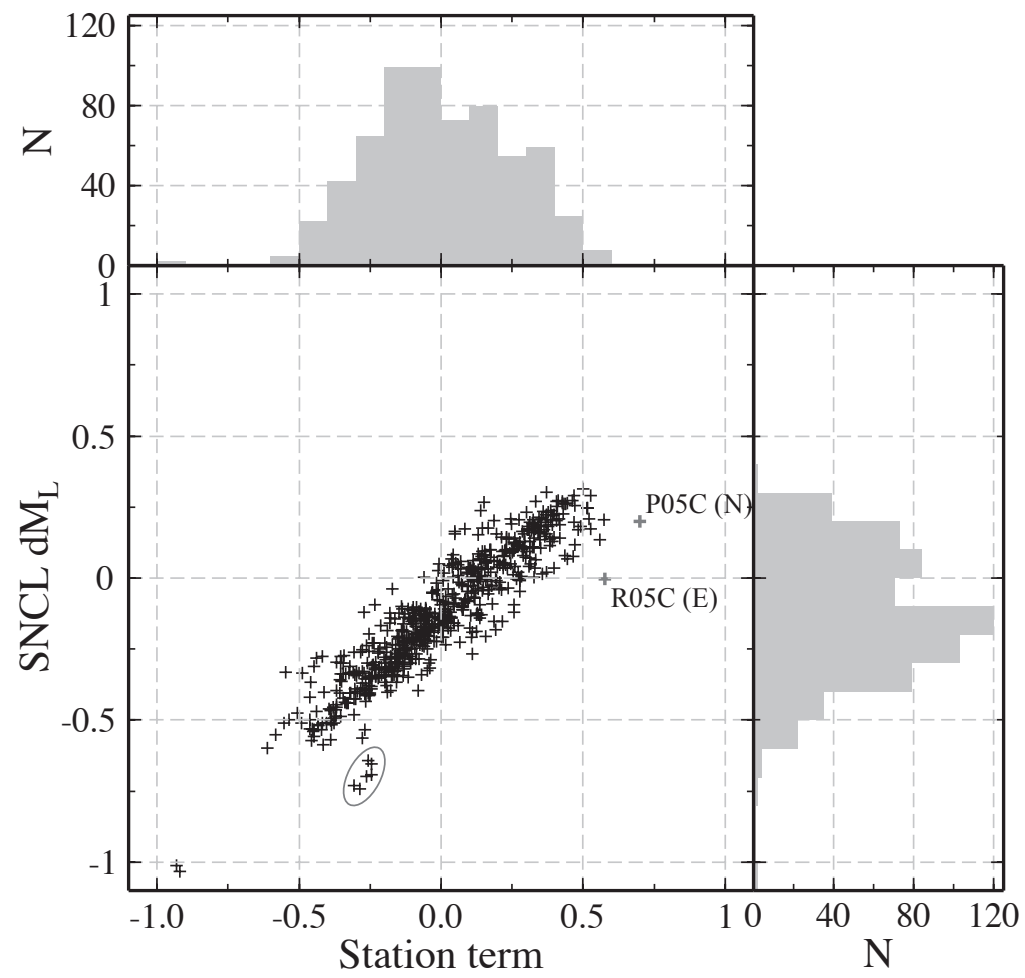

Figure 4.

Ford et al. (2009) Version 1 